\title{
Use and performance of non-invasive ventilation in Internal Medicine ward: a real-life study
}

\author{
Francesco Ventrella, Armando Giancola, Sergio Cappello, Maria Pipino, Graziano Minafra, Mattea Carbone, \\ Luigi Caccetta, Maria Insalata, Luigi Iamele
}

Internal Medicine Department, G. Tatarella Hospital, Cerignola (FG), Italy

\begin{abstract}
Controlled trials demonstrated efficacy and safety of non-invasive ventilation (NIV) in treatment of acute respiratory failure, initially in Intensive Care Units, then in other care settings (semi-intensive care units, emergency departments, and also in the wards, more often pneumological ones). Few studies have been published about NIV in Italian wards of Internal Medicine with full self-management of NIV by internists in a normal ward setting. We performed a prospective real-life study about the use of NIV in Internal Medicine ward devoid of a critical area of semi-intensive therapy, with the aim of confirming, in this setting, the effectiveness of NIV. During a period of 13 months, 42 patients with hypercapnic respiratory failure of different etiology and acidosis $(\mathrm{pH}<7.35)$ were treated by NIV. NIV was successful in $81 \%$ of patients. In-hospital mortality was $9.5 \%$. Safety of NIV is demonstrated by the absence of serious complications: only 7 patients showed poor compliance and 2 patients had facial pressure ulcer due to the mask. There were not statistical differences in success rate of NIV according to severity of acidosis at admission $(\mathrm{pH}<7.25 v s \mathrm{pH}>7.25)$, neither according to the acute physiology and chronic health evaluation II score and the national early warning score, but the modified early warning score only showed statistically significant difference with lower values in the success group: $2.82 \pm 1.57$ vs $4.13 \pm 1.46(\mathrm{P}<0.05)$. NIV has proven to be effective and safe in Internal Medicine ward.
\end{abstract}

\section{Introduction}

The treatment of hypercapnic acute respiratory failure (ARF) with acidosis generally requires the use of

Correspondence: Francesco Ventrella, Internal Medicine Department, G. Tatarella Hospital, via A. Murgolo, 71042 Cerignola (FG), Italy.

Tel.: +39.0885.419446. E-mail: f.ventrella@tiscali.it

Key words: Non-invasive ventilation; acute respiratory failure; Internal Medicine ward.

Acknowledgments: we thank our nurses Abatino Franca, Alicino Carmela, Conte Paola, Damiano Francesca, D'Elia Antonio, Di Ciomma Cosimo, Diliddo Lucia, Ducato Carmen, Granato Giuseppe, Guercia Rossella, Ladogana Andrea, Luongo Elianna, Monopoli Lucia, Perna Annalisa, Tardio Clara, Todisco Angela and Valentino Giovanni for their dedication to work and great availability to learn new skills.

Conflict of interest: the authors declare no potential conflict of interest.

Received for publication: 30 August 2014.

Revision received: 14 October 2014.

Accepted for publication: 18 October 2014.

This work is licensed under a Creative Commons Attribution NonCommercial 3.0 License (CC BY-NC 3.0).

CCopyright F. Ventrella et al., 2015

Licensee PAGEPress, Italy

Italian Journal of Medicine 2015; 9:260-267

doi:10.4081/itjm.2015.541 mechanical ventilation. Traditionally, the management of this condition was prerogative of Intensive Care Unit (ICUs) by use of invasive mechanical ventilation (IMV), after endotracheal intubation (ETI) or tracheostomy.

This technique is very effective; however, endotracheal tube is proved to be important contributor to the pathogenesis and development of complications, especially ventilator-acquired pneumonias that are known to be one of the leading causes of morbidity and mortality in ICUs. This is due to an artificial airways interference with a number of respiratory tract defense mechanisms that causes bacterial colonization of the tracheobronchial tree.

In recent decades, it has been developed a new mode of mechanical ventilation that does not require invasive introduction of a tube into the airways, but the use of an external interface, a mask or a helmet: for this reason, it has been called non-invasive ventilation (NIV). The main advantage of NIV is a reduced incidence of complications compared to invasive ventilation, thanks to the absence of a ventilatory prosthesis within the patient's airways.

Several randomized controlled trials have demonstrated efficacy and safety of NIV, with a more solid evidence for patients with ARF due to an exacerbation of chronic obstructive pulmonary disease (COPD), ${ }^{1-4}$ while for other ARF etiologies most of the studies are small and many did not include power calculations. ${ }^{5}$

Many reviews debated and confirmed the use of this technique. ${ }^{6-11}$

Management and monitoring of NIV have been well codified in several guidelines. ${ }^{12-14}$ 
Initially introduced and tested within ICUs, later NIV was also used outside ICUs, in less complex care settings, semi-ICUs, emergency departments, and also in the wards, more often pneumological ones. ${ }^{15-18}$

\section{Materials and Methods}

We performed a prospective real-life study about the use of NIV in Internal Medicine ward, equipped with medical and nursing staff having specific technical skills, but devoid of a critical area of semi-intensive therapy, with the aim of confirming, in this setting, positive results of NIV previously shown in several randomized controlled trials. It is well known that there is often a significant difference between the results of controlled clinical trials, carried out on wellselected populations, and those in real life, that apply to varied and diverse patients.

The study was performed in the Internal Medicine ward of the Hospital G. Tatarella in Cerignola (FG, Italy). The medical staff (9 units) ensures the active guard $\mathrm{H} 24$.

The physicians and nurses followed two theoretical and practical training courses on NIV. Further the nurses were subjected to on-the-job training, under the direction of experienced physicians.

The department has officially adopted a protocol of utilization of NIV, compiled according to the method of the proactive root cause analysis. ${ }^{19}$

The ward has 24 beds for acute cases and is equipped with a blood gas analyzer. The median nurse/patient ratio is $1: 8$.

Within our own hospital there is an ICU, where to transfer patients with failure of NIV, except those for which NIV is a ceiling treatment (do-not-intubate patients).

The study period extended from March 1, 2013 to March 31, 2014.

We selected all patients with hypercapnic respiratory failure of different etiology, who had $\mathrm{pH}<7.35$ with $\mathrm{pCO}_{2}>45 \mathrm{mmHg}$ and clinical signs of respiratory effort.

There were no exclusion criteria, except when it was impossible to apply NIV for absolute contraindications (apnea or severe bradypnea, engorgement of the airways for excessive secretions with ineffective cough, vomiting, facial malformations or trauma, pneumothorax or pneumomediastinum, severe hemodynamic instability) or for patient's early intolerance.

Comorbidity was measured by the age-adjusted Charlson comorbidity index (ACCI) ${ }^{20,21}$

The patients' clinical severity was measured by different prognostic scores: i) the acute physiology and chronic health evaluation II (APACHE II) score; 22 ii) the modified early warning score (MEWS), ${ }^{23}$ iii) the national early warning score (NEWS). ${ }^{24}$
APACHE II score, although applicable to medical patients, is traditionally more suitable for the evaluation of patients admitted to the ICU.

MEWS and NEWS are two systems of early warning score (EWS), selected from the 33 EWS in the literature, ${ }^{25}$ most suitable to early evaluate, outside ICUs, already in Emergency Departments, the clinical severity and the subsequent risk of death and length of hospital stay: i) MEWS, as validated by Subbe et $a l . ;^{23}$ ii) NEWS, as well as standardized in the most recent report (2012) of the British Royal College of Physicians, also adopted in Italy in the National System for the Guidelines of the National Health Institute - Tuscany region section. ${ }^{24}$

NEWS differs from MEWS especially because it assesses oxygen saturation, valuing the burden of the hypoxia and consequent need for oxygen therapy.

All patients were treated with standard drug-therapy of the disease (or diseases) cause of ARF. In particular, for patients with COPD, we have followed the Global Initiative for Chronic Obstructive Lung Disease (GOLD) guidelines and the diagnostic-therapeutic protocol of the Federation of Associations of Hospital Doctors on Internal Medicine (FADOI) Puglia $^{26}$ (systemic corticosteroids, antibiotics, inhaled short-acting bronchodilators and, as second choice in case of failure to improve with these medications, intravenous aminophylline).

NIV was implemented with oronasal mask (FlexiFit $^{\mathrm{TM}}$; Fisher \& Paykel, Auckland, New Zealand) and Elisée $^{\mathrm{TM}} 150$ ventilator (ResMed Corp., San Diego, CA, USA) in pressure support ventilation + positive end-expiratory pressure (PEEP), starting with pressure support (PS) set at $14 \mathrm{cmH}_{2} \mathrm{O}$ and PEEP at 4-5 $\mathrm{cmH}_{2} \mathrm{O}$. PS could be increased in steps of $2 \mathrm{~cm} \mathrm{H}_{2} \mathrm{O}$ ( $\max 22$ ) with the goal of a target tidal volume expired of $6 \mathrm{~mL} / \mathrm{kg}$ of weight. Even PEEP could be increased up to max 6-8 $\mathrm{cmH}_{2} \mathrm{O}$ to improve oxygenation or in the case of concomitant heart failure.

Oxygen supply was initiated with a $\mathrm{FiO}_{2}$ of 24$28 \%$ and titrated to achieve a target of $\mathrm{SatO}_{2}$ of 88 $92 \%$, according to the British Thoracic Society guidelines. ${ }^{27}$

In the first day, NIV was continued uninterruptedly for as many hours as possible according to patient's tolerance; in the following days it was carried out with cycles of 2-3 $\mathrm{h}$ in the morning, 2-3 $\mathrm{h}$ in the afternoon and throughout the night, proceeding to a progressive lengthening of the period of interruption and contextual step-down of the pressure values of $2 \mathrm{cmH}_{2} \mathrm{O}$, according to arterial blood gas (ABG) analysis.

In the first 15-20 min of NIV, patients are kept under medical and/or nursing observation with control of $\mathrm{SpO}_{2}$ by fingertip pulse oximeter; then, in the first hours, they are checked every 15-30 min depending on their adaptation to ventilation. The subsequent 
checks take place, as usual, on the basis of patients' clinical conditions.

ABG were performed before starting NIV, after 1$2 \mathrm{~h}$, and then at least every $24 \mathrm{~h}$. Any further ABG were performed according to clinical needs of individual patient. $\mathrm{SpO}_{2}$, electrocardiogram, heart rate, respiratory rate $(\mathrm{RR})$, blood pressure were monitored.

Patients with ARF due to pneumonia, especially if younger and with $\mathrm{pH}<7.25$, have been subjected to more stringent controls and evaluated together with the intensivist at the first signs of lack of improvement or worsening for eventual transfer to the ICU.

NIV was considered of success if, within the first two hours, were obtained: i) increase of $\mathrm{pH}$; ii) reduction of $\mathrm{pCO}_{2}, \mathrm{RR}$, dyspnea and respiratory effort; iii) sensory improvement.

Criteria of failure of NIV were, within the first 2 h: i) $\mathrm{pH}$ not improved or worsened; increase in $\mathrm{pCO}_{2}$; ii) $\mathrm{SaO}_{2}<88 \%$ and $\mathrm{pO}_{2}<60 \mathrm{mmHg}$; iii) $\mathrm{P} / \mathrm{F}<180$; iv) $\mathrm{RR}>30 / \mathrm{m}$.

\section{Results}

In 13 months, a total of 140 patients with ARF (diagnosis-related group classification: class no. 087) were admitted to our department.

Of these, 88 had hypoxemic ARF (60 treated by oxygen using Venturi mask, 28 treated by continuous positive airway pressure) and 52 had hypercapnic ARF (including 10 without respiratory acidosis and 42 with respiratory acidosis) (Figure 1).

These latter have been subject of the present study. It is a population of 42 patients ( 20 males, 22 females), who presented hypercapnic ARF with acidosis $\left(\mathrm{pCO}_{2}>45 \mathrm{mmHg}\right.$ and $\left.\mathrm{pH}<7.35\right)$ and associated clinical signs of respiratory effort.

Table 1 summarizes characteristics of age, co-morbidity, clinical severity and etiology of ARF of the patients evaluated in our study. We emphasize the wide variety of etiologies of ARF.

There were no differences between genders, except for age, higher in women $(81 \pm 13$ years) than males ( $76 \pm 14$ years).

All selected patients were treated by NIV. The results of treatment are summarized in Table 2.

NIV was successful in 34 of 42 patients $(81 \%)$, with resolution of ARF and discharge home.

For 1 patient $(2.38 \%)$ it was necessary the ETI and transfer to the intensive care unit for invasive mechanical ventilation: after 11 days of IMV and 17 days of hospitalization in intensive care, this patient was retransferred in our department for additional treatment with NIV, then stabilized and discharged home.

One patient, although not yet stabilized during NIV, on request of his family was transferred to another hospital closer to the town of their residence.

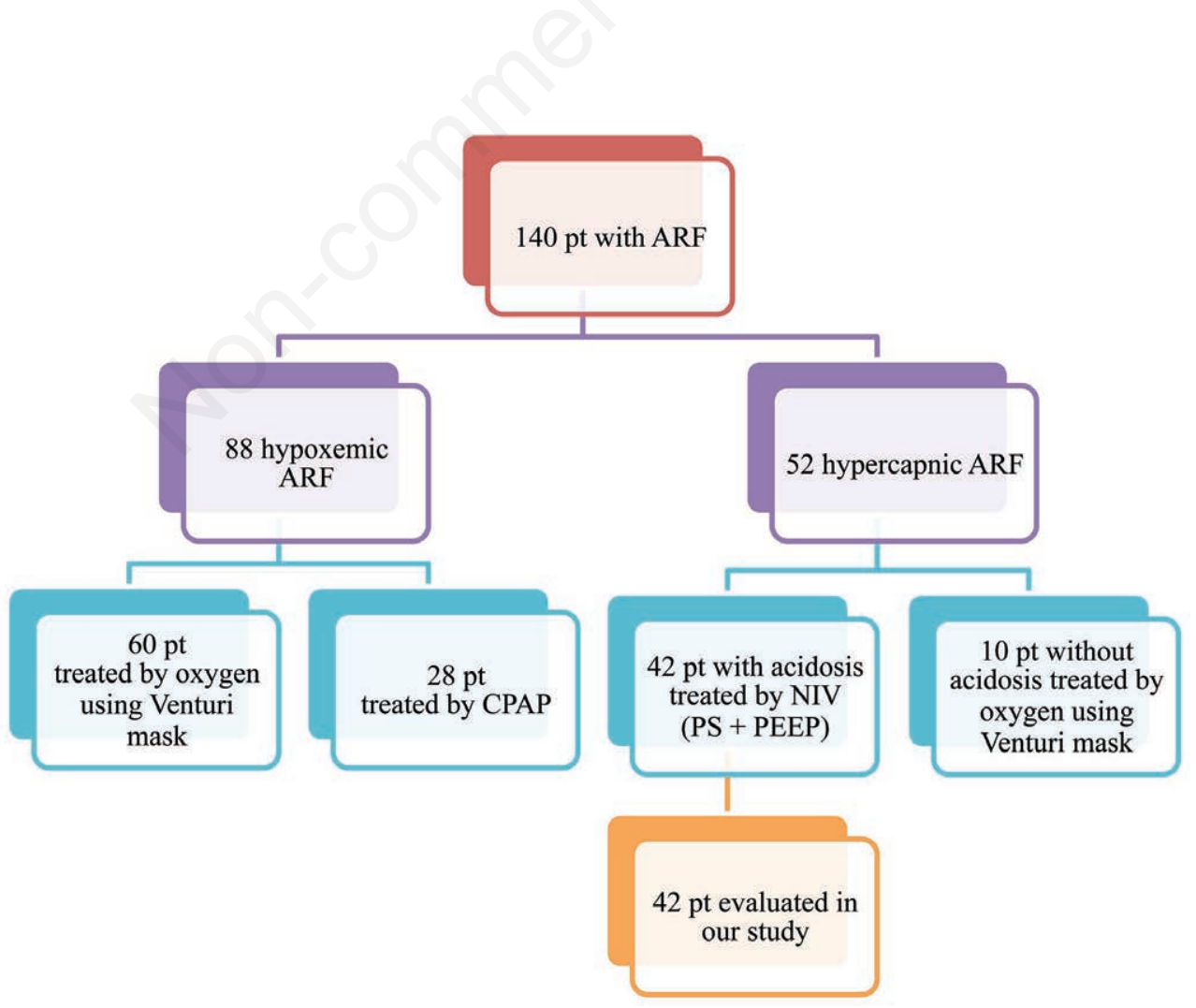

Figure 1. Flow-chart of patients (pt) with acute respiratory failure (ARF) hospitalized in 13 months. CPAP, continuous positive airway pressure; NIV, non-invasive ventilation; PS, pressure support; PEEP, positive end-expiratory pressure. 
For 2 patients (in critical conditions), discharge against medical advice has been requested, resulting in discontinuation of NIV.

In 4 patients $(9.5 \%)$ occurred the death (etiologies of respiratory failure were respectively: in 2 cases heart failure, in 1 case COPD and in 1 case pneumonia).
The specific causes of death were: i) for 2 patients, acute renal failure (in one case associated with gastrointestinal bleeding); ii) for 1 patient, multi-organ failure; iii) for 1 patient, intestinal infarction (this patient had initially responded favorably to NIV, so as to be considered programmable for an upcoming discharge

Table 1. Population characteristics at enrollment.

\begin{tabular}{|c|c|c|}
\hline \multirow[b]{2}{*}{ Characteristics } & \multicolumn{2}{|c|}{42 pts (M 20, F 22) } \\
\hline & $\operatorname{Mean} \pm$ SD & Range \\
\hline Age & $79 \pm 13$ & $(35-98)$ \\
\hline Charlston index & $7 \pm 2$ & $(3-11)$ \\
\hline APACHE II & $21 \pm 5$ & $(10-32)$ \\
\hline MEWS & $3 \pm 2$ & $(1-6)$ \\
\hline NEWS & $8 \pm 2$ & $(3-13)$ \\
\hline Kelly scale & 3 & $1-4$ \\
\hline $\mathrm{pH}$ & $7.23 \pm 0.07$ & $(7.03-7.34)$ \\
\hline $\mathrm{pCO}_{2}$ & $82 \pm 16$ & $(59-120)$ \\
\hline $\mathrm{pO}_{2}$ & $62 \pm 22$ & $(29-122)$ \\
\hline $\mathrm{HCO}_{3}^{-}$ & $34 \pm 7$ & $(23-46)$ \\
\hline $\mathrm{PaO}_{2} / \mathrm{FiO}_{2}$ & $198 \pm 71$ & $(106-378)$ \\
\hline Etiology of respiratory failure & No. & $\%$ \\
\hline Exacerbation of COPD & $18^{*}$ & 42.8 \\
\hline Heart failure & 9 & 21.4 \\
\hline Pneumonia & 5 & 11.9 \\
\hline Obesity hypoventilation syndrome & 4 & 9.5 \\
\hline Pleural effusion + heart failure & 2 & 4.8 \\
\hline Interstitial lung disease & 2 & 4.8 \\
\hline Severe kyphoscoliosis & 1 & 2.4 \\
\hline Iatrogenic intoxication & 1 & 2.4 \\
\hline Total & 42 & - \\
\hline
\end{tabular}

Table 2. Results of non-invasive ventilation.

\begin{tabular}{lcc}
\hline & No. & $\mathbf{\%}$ \\
\hline Discharge home & 34 & 80.95 \\
\hline In-hospital mortality* & 4 & 9.52 \\
\hline Transfer to Intensive Care Unit for invasive ventilation & 1 & 2.38 \\
\hline Transfer to another hospital $^{\circ}$ & 1 & 2.38 \\
\hline Discharge against medical advice & 2 & 4.76 \\
\hline Total & 42 & 100.00 \\
\hline
\end{tabular}

*Cause of death: no. 1 acute renal failure; no. 1 intestinal infarction; no. 1 multi-organ failure; no. 1 gastrointestinal bleeding and acute renal failure. In the 4 patients who died, the causes of respiratory failure were: no. 1 chronic obstructive pulmonary disease, no. 1 pneumonia, no. 2 heart failure; ${ }^{\circ}$ Cause of transfer: request of family members to approach their residence. 
home; however, the onset of intestinal infarction caused the reappearance of respiratory failure, which has no longer responded to any treatment).

In patients who responded favorably to NIV, arterial blood gas parameters are shown in Table 3 .

ABG performed within the first $2 \mathrm{~h}$ of NIV already shows favorable response to treatment, with improvement of respiratory acidosis. In the majority of patients ( 27 of 34 , i.e., $79 \%$ of the total), respiratory acidosis was fully corrected within $24 \mathrm{~h}$ from the start of the NIV, while in 7 patients $(21 \%)$ more time has been needed. All $\mathrm{pH}$ variations between admission, $2 \mathrm{~h}$ and $24 \mathrm{~h}$ were statistically significant at the Student's $t$ test (Figure 2).

We proceeded to a comparative assessment of patients according to severity of respiratory acidosis at admission: group A $(\mathrm{pH}<7.25)$ and group B ( $\mathrm{pH}>7.25$ ), numerically quite similar (respectively, 22 vs 20 patients). As shown in Table 4, by reading of the raw data, group A seemed to present a lower success rate of NIV (72.73\%) compared to the best results in group B ( $90 \%$ success). However, this difference is not statistically significant (chi-square test) $(\mathrm{P}=0.16)$.

The comparison of prognostic scores of clinical severity between patients with successful $v s$ failure of NIV is shown in Table 5.

There were no serious complications of NIV: 7 patients showed poor compliance; 2 patients had facial pressure ulcer due to the mask.

\section{Discussion}

In recent years, several surveys have been carried out to evaluate use of NIV in different health care settings; these surveys have shown a gradual evolution from a substantial under-utilization of NIV ${ }^{28-31}$ to its gradual spread in different geographical areas, although with high heterogeneity between different hospitals and different specialists (intensive care physicians, emergency physicians, pulmonologists, internal medicine physicians). ${ }^{32-35}$

Few studies ${ }^{36,37}$ have been published on use of NIV

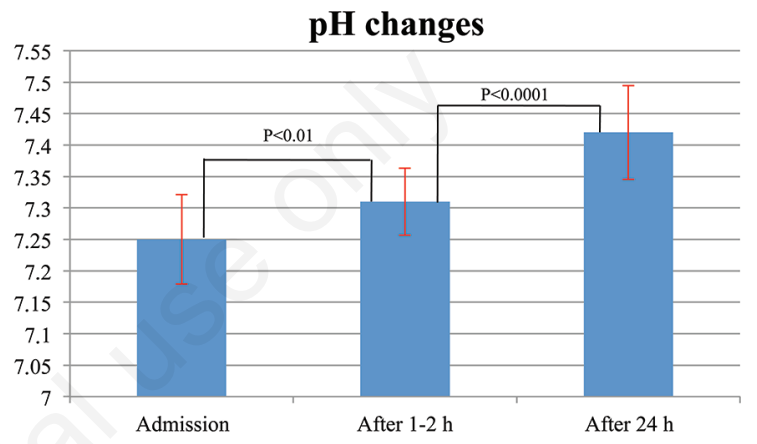

Figure 2. Statistical analysis of pH variations ( $t$ test) during non-invasive ventilation.

Table 3. Changes of arterial blood gas during non-invasive ventilation in responding patients.

\begin{tabular}{lcccc}
\hline & \multicolumn{1}{c}{ T0 } & T2 & T24 & At discharge \\
\hline $\mathrm{pH}$ & $7.24 \pm 0.07(7.03-7.34)$ & $7.31 \pm 0.07(7.03-7.41)$ & $7.42 \pm 0.07(7.30-7.54)$ & $7.45 \pm 0.04(7.37-7.52)$ \\
\hline $\mathrm{pCO}_{2}$ & $82 \pm 17(120-59)$ & $71 \pm 18(115-47)$ & $56 \pm 10(91-42)$ & $58 \pm 8(79-39)$ \\
\hline $\mathrm{HCO}_{3}^{-}$ & $34 \pm 7(23-45)$ & $35 \pm 7(23-47)$ & $36 \pm 5(26-47)$ & $40 \pm 7(53-27)$ \\
\hline $\mathrm{PaO}_{2} / \mathrm{FiO}_{2}$ & $203+72(106-378)$ & - & - & $248+54(141-390)$ \\
\hline
\end{tabular}

Table 4. Comparison according to the severity of respiratory acidosis.

\begin{tabular}{|c|c|c|c|c|c|}
\hline & \multicolumn{2}{|c|}{$\begin{array}{c}\mathrm{pH}<7.25 \\
22 \mathrm{pts}\end{array}$} & \multicolumn{2}{|c|}{$\begin{array}{c}\mathrm{pH} \geq 7.25 \\
20 \mathrm{pts}\end{array}$} & \multirow[t]{2}{*}{ chi-square test } \\
\hline & No. & $\%$ & No. & $\%$ & \\
\hline Discharged home & 16 & 72.73 & 18 & 90.00 & $\mathrm{P}=0.16$ \\
\hline Dead & 3 & 13.64 & 1 & 5.00 & \\
\hline Transferred to Intensive Care Unit for invasive ventilation & 1 & 4.55 & - & - & \\
\hline Transferred to another hospital & - & - & 1 & 5.00 & \\
\hline Discharged against medical advice & 2 & 9.09 & - & - & \\
\hline
\end{tabular}

pts, patients. 
in Italian wards of Internal Medicine with full selfmanagement of NIV by internists in a normal ward setting, i.e., without Critical Area of Internal Medicine or High Dependency Unit (HDU).

Yet it is precisely the Internal Medicine wards that, due to their greater spread in all hospitals, can provide an easier and more widespread accessibility to a broader population, as well as its application in early phase of evolution of ARF with mild or mild to moderate respiratory acidosis, with greater chance of success.

The aim of our study is not to demonstrate, with rigorous scientific methodology, the efficacy of NIV, because of its several methodological limitations: few and poorly selected patients, lack of control group, absence of follow-up in the long term, different and often multiple etiologies of ARF, among which it is not always easy to distinguish the prevalent etiology.

But it is precisely these defects may be the added value of our study in the demonstration of effectiveness of NIV, i.e., to confirm that NIV, whose efficacy has already been sufficiently demonstrated in several randomized controlled trials, can be used with success in the real world of our Internal Medicine wards, generally devoid of a typical organization of semi-intensive unit, in patients poorly selected and with many comorbidities.

In this objective, our data should be added and compared to those of the few other studies carried out in Italy in similar conditions. ${ }^{36,37}$

Compared to the pilot study of La Regina and colleagues, ${ }^{37}$ with which we share the variety of etiologies of ARF, in patients with hypercapnic ARF our data indicate a slightly higher success rate $(80.9 \% v s$ $68.8 \%$ ), more similar to that reported by Fiorino and colleagues $^{36}(85 \%)$ and also in the English study of Balami $^{38}(79 \%)$. These last two studies, however, are derived from a population of ARF with unique etiology due to COPD and, in the study of Balami, in the presence of HDU.

Particularly low is our in-hospital mortality $(9.52 \%)$, lower than the one reported by La Regina and colleagues ${ }^{37}(27.6 \%)$; this difference is maintained also if you add to the 4 patients who died also the 2 patients discharged against medical advice (14.28\%).
The lower age of our patients compared to those of the study of La Regina (79 vs 87.7 years) could account this difference, while there are not significant differences between ABG at admission.

Mean age of patients ( 78 years) and in-hospital mortality $(14.81 \%)$ reported by Fiorino ${ }^{36}$ are similar to ours.

One of the main objections against NIV is that it may delay intubation, leading to a worse outcome. Therefore, of particular interest is the ability to predict patients likely to fail with NIV.

These patients would be spared the discomfort of NIV and intubation would not be delayed.

Alternatively, high probability of failure of NIV could be used to decide where a trial of NIV should take place, i.e., in the ICU, whereas the patient who is likely to be successfully treated with NIV can be managed in the ward. Unfortunately, analysis of studies led to inconclusive results. ${ }^{39,40}$

In this context, we made a comparison of some parameters between the groups, respectively, with success or failure of NIV. Since acidosis is one of main indicators of severity of ARF, whose greater worsening may indicate higher probability of failure of $\mathrm{NIV}^{41,42}$ we looked for a possible difference in success rate of NIV in our patients according to severity of acidosis at admission $(\mathrm{pH}<7.25 v s \mathrm{pH}>7.25)$. The difference, although present $(72.73 \%$ in group with $\mathrm{pH}<7.25$ vs $90 \%$ in group with $\mathrm{pH}>7.25$ ) was not statistically significant. In this, our data coincide with those reported in the three other studies conducted in the Departments of Internal Medicine. ${ }^{36-38}$

Also if you set the cut-off at $\mathrm{pH}$ of 7.20 (instead of 7.25), likewise it does not make any statistically significant difference.

The examination of prognostic scores at admission (APACHE II, MEWS, NEWS) may be of some interest. The comparison between the group with success and that with the failure of NIV indicates that the difference of MEWS score is statistically significant between the two groups, with lower values in the success group: $2.82 \pm 1.57$ vs $4.13 \pm 1.46(\mathrm{P}<0.05)$. Instead, the APACHE II score and NEWS score do not show statistically significant differences.

Table 5. Comparison of prognostic scores between patients with success of non-invasive ventilation (NIV) vs patients with failure of NIV.

\begin{tabular}{lccc}
\hline & Success & Failure & Statistical analysis (t test) \\
\hline APACHE II & $20.44( \pm 5.42)$ & $23.63( \pm 5.53)$ & $\mathrm{ns}(\mathrm{P}=0.14)$ \\
\hline MEWS & $2.82( \pm 1.57)$ & $4.13( \pm 1.46)$ & $\mathrm{P}<0.05$ \\
\hline NEWS & $8.56( \pm 2.08)$ & $9.38( \pm 3.02)$ & $\mathrm{ns}(\mathrm{P}=0.36)$ \\
\hline
\end{tabular}

APACHE II, acute physiology and chronic health evaluation II; MEWS, modified early warning score; NEWS, national early warning score; ns, not significant. 


\section{Conclusions}

Our real life study confirm that NIV is effective and safe for the treatment of hypercapnic ARF also in Internal Medicine wards devoid of Critical Area or HDU.

The introduction of NIV in these wards, as well as immediately improving the management of patients with ARF, may also create conditions for possible future changes in the organization and structure of the department, that make the creation of Critical Area of Internal Medicine (semi-ICU) possible, with further improvement of level of care.

In wards where NIV is regularly used, it is necessary to adopt a specific protocol in regards to indications, contraindications, method of delivery, monitoring and weaning. It is also desirable that there is an internal quality control, with identification both of one or more indicators both of a standard of care, with recording of patients' data and outcomes of NIV.

Do not forget, finally, that you have to be aware of your own limitations and you have to know with clarity when you must call intensive care physicians.

\section{References}

1. Brochard L, Mancebo J, Wysocki M, et al. Noninvasive ventilation for acute exacerbations of chronic obstructive pulmonary disease. N Engl J Med 1995;333:817-22.

2. Kramer N, Meyer TJ, Meharg J, et al. Randomized, prospective trial of noninvasive positive pressure ventilation in acute respiratory failure. Am J Respir Crit Care Med 1995;15:1799-806.

3. Plant PK, Owen JL, Elliott MW. Early use of non-invasive ventilation for acute exacerbations of chronic obstructive pulmonary disease on general respiratory wards: a multicentre randomised controlled trial. Lancet 2000;355:1931-5.

4. Collaborative Research Group of Noninvasive Mechanical Ventilation for Chronic Obstructive Pulmonary Disease. Early use of non-invasive positive pressure ventilation for acute exacerbations of chronic obstructive pulmonary disease: a multicentre randomized controlled trial. Chinese Med J 2005;118:2034-40.

5. Keenan SP, Mehta S. Noninvasive ventilation for patients presenting with acute respiratory failure: the randomized controlled trials. Respir Care 2009;54: 116-26.

6. Keenan SP, Sinuff T, Cook DJ, Hill N. When is the addition of noninvasive positive pressure ventilation effective in acute exacerbations of COPD? A systematic review. Ann Intern Med 2003;138:861-70.

7. Ram FS, Picot J, Lightowler J, Wedzicha JA. Non-invasive positive pressure ventilation for treatment of respiratory failure due to exacerbations of chronic obstructive pulmonary disease. Cochrane Database Syst Rev 2004; (3):CD004104.

8. Elliott MW. Noninvasive ventilation in acute exacerbations of COPD. Eur Respir Rev 2005;14:94,39-42.

9. Hill NS, Brennan J, Garpestad E, Nava S. Noninvasive ventilation in acute respiratory failure. Crit Care Med 2007;35:2402-7.

10. Nava S, Hill N. Non-invasive ventilation in acute respiratory failure. Lancet 2009;374:250-9.

11. Williams JW, Cox CE, Hargett CW, et al. Noninvasive positive-pressure ventilation (NPPV) for acute respiratory failure. Agency for Healthcare Research and Quality (US) Comparative Effectiveness Reviews. Rockville (MD): 2012 Jul. Report No.: 12-EHC089-EF. Available from: www.ncbi.nlm.nih.gov/pubmedhealth/PMH0047897/

12. International Consensus Conferences in Intensive Care Medicine: non-invasive positive pressure ventilation in acute respiratory failure. Organised jointly by the American Thoracic Society, the European Respiratory Society, the European Society of Intensive Care Medicine, and the Société de Réanimation de Langue Française, and approved by the ATS Board of Directors. Am J Respir Crit Care Med 2001;163:283-91.

13. British Thoracic Society Standards of Care Committee. BTS guideline - Noninvasive ventilation in acute respiratory failure. Thorax 2002;57:192-211.

14. Keenan SP, Sinuff T, Burns KE, et al. Clinical practice guidelines for the use of noninvasive positive-pressure ventilation and noninvasive continuous positive airway pressure in the acute care setting. CMAJ 2011;183:E195E214.

15. Elliott MW, Confalonieri M, Nava S. Where to perform noninvasive ventilation? Eur Respir J 2002;19:1159-66.

16. Chiumello D, Conti G, Foti G, et al. Non-invasive ventilation outside the intensive care unit for acute respiratory failure. Minerva Anestesiol 2009;75:459-66.

17. Cabrini L, Monti G, Villa M, et al. Non-invasive ventilation outside the Intensive Care Unit for acute respiratory failure: the perspective of the general ward nurses. Minerva Anestesiol 2009;75:427-33.

18. Mclaughlin KM, Murray IM, Thain G, Currie GP. Wardbased non-invasive ventilation for hypercapnic exacerbations of COPD: a 'real-life' perspective. Q J Med 2010;103:505-10.

19. Perilli G. Root cause analysis proattiva. Milano; Ed. Il Sole 24 Ore; 2011. Available from: http:/www.rcap.it/en/

20. Charlson ME, Pompei P, Ales KL, MacKanzie CR. A new method of classifying prognostic comorbidity in longitudinal studies: development and validation. J Chron Dis 1987;40:373-83.

21. Charlson M, Szatrowski TP, Peterson J, Gold J. Validation of a combined comorbidity index. J Clin Epidemiol 1994;47:1245-51.

22. Knaus WA, Draper EA, Wagner DP, Zimmerman JE. APACHE II: a severity of disease classification system. Crit Care Med 1985;13:818-29.

23. Subbe CP, Kruger M, Rutherford P, Gemmel L. Validation of a modified Early Warning Score in medical admissions. Q J Med 2001;94:521-6.

24. Royal College of Physician. National early warning score (NEWS). Standardising the assessment of acuteillness severity in the NHS. Report of a working party. London: RCP, 2012. Available from: www.rcplondon. ac.uk/national-early-warning-score (Italian version: www.regione.toscana.it/consiglio-sanitario-regionale/ linee-guida)

25. Smith GB, Prytherch DR, Schmidt PE, Featherstone PI. Review and performance evaluation of aggregate 
weighted 'track and trigger' systems. Resuscitation 2008;77:170-9.

26. Errico M, Mastroianni F, Ventrella F. Protocollo diagnostico-terapeutico del paziente internistico con riacutizzazione di bronco-pneumopatia cronica ostruttiva: dall'arrivo in ospedale alla dimissione. Ital $\mathrm{J}$ Med 2013;7(s5):1-42.

27. O'Driscoll BR, Howard LS, Davison AG; on behalf of the British Thoracic Society. BTS guideline for emergency oxygen use in adult patients. Thorax 2008;63:vi1-68.

28. Doherty MJ, Greenstone MA. Survey of non-invasive ventilation (NIPPV) in patients with acute exacerbations of chronic obstructive pulmonary disease (COPD) in the UK. Thorax 1998;53:863-6.

29. Burns KE, Sinuff T, Adhikari NK, et al. Bilevel noninvasive positive pressure ventilation for acute respiratory failure: survey of Ontario practice. Crit Care Med 2005;33:1477-83.

30. Maheshwari V, Paioli D, Rothaar R, Hill NS. Utilization of noninvasive ventilation in acute care hospitals - a regional survey. Chest 2006;129:1226-33.

31. Bierer GB, Soo Hoo GW. Noninvasive ventilation for acute respiratory failure: a national survey of Veterans Affairs Hospitals. Respir Care 2009;54:1313-20.

32. Walkey AJ, Wiener RS. Use of noninvasive ventilation in patients with acute respiratory failure, 2000-2009. A population-based study. Ann Am Thorac Soc 2013;10:10-7.

33. Crimi C, Noto A, Princi P, et al. A European survey of noninvasive ventilation practices. Eur Respir J 2010;36: 362-9.

34. Cabrini L, Antonelli M, Savoia G, Landriscina M. Noninvasive ventilation outside of the intensive care unit: an Italian survey. Minerva Anestesiol 2011;77:313-22.

35. Wang S, Singh B, Lin Tian L, et al. Epidemiology of noninvasive mechanical ventilation in acute respiratory failure. A retrospective population-based study. BMC Emerg Med 2013;13:6.

36. Fiorino S, Detotto E, Battilana M, et al. Severe exacerbations of chronic obstructive pulmonary disease: management with noninvasive ventilation on a general medicine ward. Ital J Med 2010;4:173-8.

37. La Regina M, Marinaro A, Scuotri L, et al. Non-invasive mechanical ventilation in internal medicine departments: a pilot study. Ital J Med 2013;7:172-8.

38. Balami JS, Packham SM, Gosney MA. Non-invasive ventilation for respiratory failure due to acute exacerbations of chronic obstructive pulmonary disease in older patients. Age Ageing 2006;35:75-9.

39. Lightowler JVJ, Elliott MW. Predicting the outcome from NIV for acute exacerbations of COPD. Thorax 2000;55:815-6.

40. Conti V, Terzano C, Mollica C, et al. Predictors of outcome in COPD patients with hypercapnic respiratory failure requiring NIV. J Anesthesiol Crit Care Med 2014;1:1-7.

41. Plant PK, Owen JL, Elliott MW. Non-invasive ventilation in acute exacerbations of chronic obstructive pulmonary disease: long term survival and predictors of in-hospital outcome. Thorax 2001;56:708-12.

42. Confalonieri M, Garuti G, Cattaruzza MS, et al. Italian noninvasive positive pressure ventilation (NPPV) study group. A chart of failure risk for noninvasive ventilation in patients with COPD exacerbation. Eur Respir J 2005;25:348-55. 